\title{
Monstros e monstruosidades em As traquínias de Sófocles
}

\author{
Luíza Monteiro de Castro Silva Dutra \\ FALE-UFMG \\ izamonteiro@yahoo.com.br
}

\begin{abstract}
In this paper, I present some considerations about the monsters and monstrosities found in Sophocles' Trachiniae. I try to understand them not as mere decorative elements, but as essential characters, as they evoke the borderline between man and beast, and compel us to rethink our conceptions of human nature. The monsters are described in the play as very rough hybrid beings, who inhabit faraway places. But the monstrosity may be also viewed as the outcome of passion, of the destructive power of Eros and Cypris. And is just through this power that the main event of the play happens: Heracles' antithetic transformation from a hero to a monster.
\end{abstract}

KEYWORDS: Greek drama (tragedy); Sophocles; monsters and monstrosities; hybrids; Heracles.

Com certa frequência, as tragédias gregas servem de morada a assombrosos monstros sob forma humana. Não é que sejam seres fantásticos, disformes ou dotados de graves deformidades físicas: parecem-nos criaturas monstruosas por conta de seu desequilíbrio e dos atos cruéis que são capazes de cometer. Passaram decerto por uma sorte de processo de monstrificação que fez deles assassinos frios e violentos - por vezes de membros de suas próprias famílias. Eurípides e Ésquilo construíram retratos memoráveis de mulheres vingadoras que poucos hesitam em chamar de monstros: Clitemnestra, em Agamêmnon e Coéforas, Medeia e Hécuba, nas tragédias homônimas. Essas mulheres, que uma cólera motivada por diferentes razões levou ao desejo de vingança, sofrem processos de animalização/monstrificação ao longo das peças, em que se vão revelando seus instintos bestiais ora associados a figuras de animais - como a cadela, no caso de Hécuba -, ora a monstros mitológicos - como a Cila, vinculada a todas as três mulheres. De fato, "no imaginário da tragédia, uma mulher que ocupa o rol normativamente masculino do executor da vingança só pode ser pensada em termos de monstruosidade". ${ }^{1}$ Aquela que "ultrapassa as fronteiras de seu papel de gênero arrisca tornar-se uma Cila” pois que "a identidade sexual 'desviante' está igualmente sujeita ao processo de sua transformação em monstro". ${ }^{2}$ Em adição, ao menos no caso de Hécuba, o próprio autor qualifica algumas personagens como monstros. Dirige-se a Hécuba e a

\footnotetext{
${ }^{1}$ Cf. Cidre, E. R. La mujer vengadora como monstruo. La deshumanización de Hécuba en la obra homónima de Eurípides. Argos. Buenos Aires, n. 26, p. 133, 2002.

${ }^{2}$ Cf. Cohen, J. J. A cultura dos monstros: sete teses. In: Donald, J.; Hunter, I.; Cohen, J. J.; Gil, J. Pedagogia dos Monstros. Os prazeres e os perigos da confusão de fronteiras. Tradução de Tomaz Tadeu da Silva. Belo Horizonte: Autêntica, 2000, p. 35.
} 
seu séquito - e mesmo a Polimestor - com o vocábulo $\theta \hat{p} \rho$, que mais do que situá-los no campo da selvageria animal, fá-lo no registro do monstruoso, igualmente uma das acepções do termo. ${ }^{3}$

O estoico romano Sêneca plasmou com apuro as rijas formas da cólera monstrificante em personagens de suas tragédias. Não só o fez como ainda dedicou todo um tratado filosófico sobre essa afecção, onde prescreve uma terapêutica muitíssimo detalhada e repetitiva. Como cultor das duas áreas, soube minuciosamente imprimir nos diálogos o caráter irracional das paixões da alma, dando sempre destaque para a que julgava ser a pior e mais monstruosa delas, a cólera. Descreve no tratado De ira os seus sintomas visíveis: o centelhar dos olhos, o rosto arrebatado, os lábios descorados, os dentes a ranger, os cabelos arrepiados, a respiração forçada, o peito palpitante, as mãos irrequietas, gemidos e grunhidos dum falar entrecortado à base de palavras pouco moduladas - indicações que certamente conviriam como didascália às suas peças. Os sintomas aqui listados são pelo próprio Sêneca comparados aos que se percebe em animais em véspera de um ataque: espumam os focinhos dos javalis, rugem os leões, incham os colos das serpentes enraivecidas e sombrio é o aspecto dos cães furiosos. ${ }^{4} \mathrm{~A}$ semelhança não é sem razão. No entendimento do estoico, se por um lado não há na alma sadia uma só parte não ocupada pela razão, por outro, numa alma tomada pela cólera não resta à razão qualquer lote. Daí a capacidade das paixões de tornar os homens por elas invadidos tão semelhantes a bestas.

Mas os seres humanos que cruzam as fronteiras da civilização e da razão na direção dos instintos primitivos que também lhes são intrínsecos, ainda que possam figurar como animais, jamais abandonam por completo a natureza humana. A figura do monstro vem mais a calhar: ultrapassa o raciocínio simplista do homem tornado animal, marcando o hibridismo característico dos humanos e os limites entre as naturezas de que são compostos. Os monstros habitam nessas regiões limítrofes, onde suas essências perturbadoramente anômalas e mistas anunciam uma crise de categorias.

Tratarei aqui da região fronteiriça que ocupam os monstros. Mas não me ocuparei dos já citados tragediógrafos Eurípides, Ésquilo e Sêneca, a despeito de terem

\footnotetext{
${ }^{3}$ Recebem também a predicação com o vocábulo $\theta \hat{n} \rho$ a esfinge em Sete contra Tebas de Ésquilo (v. 558), o centauro Nesso (v. 556, 568, 662, 680, 707, 935, 1162) e Erimanto (v. 1097), nas Traquínias de Sófocles, e os sátiros no Ciclope de Eurípides (v. 624).

${ }^{4}$ Cf. Sêneca, De ira, I, 1, 6.
} 
moldado muito bem as feições da alma encolerizada. Nosso objeto será a peça As traquínias, de Sófocles, que aborda a monstruosidade de uma forma bastante particular.

A peça possui muitos pontos de convergência com outras tragédias de Sófocles: a importância dada aos oráculos; indícios dramáticos tais como a saída de cena de Dejanira para o suicídio, presentes em Édipo Rei e Antígona, ou o confronto entre o Mensageiro e Licas, que lembra a discussão entre o Mensageiro de Corinto e o Servo de Tebas, em Édipo Rei; a caracterização da personagem de Dejanira, muito semelhante à da Alceste da peça homônima etc... Entretanto, apesar dos paralelos a peça não é tida como típica tragédia sofocleana, em especial quando se tem em vista o ideal clássico de um Sófocles equilibrado, brando e elevado. A presença de dois pólos, de duas partes distintas, ou mesmo de duas personagens centrais torna a peça uma exceção. É exceção à "fórmula" sofoclena recorrente em seis de suas tragédias (Ájax, Antígona, Filoctetes, Édipo Rei, Édipo em Colono e Electra $)^{5}$ na qual, como aponta Bernard Knox, o herói

vê-se em face de uma escolha entre o desastre possível (ou certo) e um compromisso que, se aceito, irá trair a concepção de si mesmo do herói, seus direitos, seus deveres. O herói decide-se contra o compromisso e essa decisão é, então, atacada, por conselhos de amigos, por ameaças, pela força. Mas ele recusa-se a ceder; mantémse verdadeiro consigo mesmo, com sua phýsis, com a "natureza" que herdou de seus parentes e que é a sua identidade. A partir dessa resolução origina-se a tensão dramática. ${ }^{6}$

Em todas as seis tragédias citadas, o herói trágico é personagem central e comanda a cena. Mas, em As traquínias, a tônica é dada por dois: Héracles e Dejanira. ${ }^{7}$ Dejanira vive uma tragédia doméstica e insere-se num mundo civilizado de emoções humanas, enquanto Héracles não se vê desligado de seu passado mítico e dos poderes da natureza que outrora dominara. Mas ambos têm uma relação profunda de

\footnotetext{
5 Usamos o termo "fórmula", mas não há que se pensar na anulação da singularidade e vitalidade particular de cada uma dessas peças e de seus heróis, bastante distintos.

${ }^{6}$ Cf. Knox, B. The heroic temper. Studies in sophoclean tragedy. Berkeley and Los Angeles: University of California Press, 1992, p. 8 (minha tradução).

${ }^{7}$ Os críticos divergem quanto a isso. Há quem questione quem é, na verdade, o héroi da peça ou mesmo quem levante a hipótese de não haver nela herói algum. Acreditamos, como Charles Segal, que "aqueles que sustentam a interdependência e complementaridade das duas figuras, como Bowra, Albin Lesky, Reinhardt e outros fizeram, estão provavelmente mais perto da verdade" (cf. Segal, C. Heroic values in the "Trachinian Women". In: Sophocles' tragic world. Divinity, nature, society. Cambridge, Mass.: Harvard University Press, 1998, p. 28 - minha tradução).
} 
complementaridade, ${ }^{8}$ a que se chama Eros ou Cípris e une-os num destino "que só na aparência é autônomo e os separa".

Héracles, embora se ajuste de certa forma ao molde de herói trágico, só desponta no êxodo da peça, quando já está a morrer; e não surgem situações que necessitem de uma deliberação do herói entre uma coisa e outra. Quanto a Dejanira, compartilha com Édipo alguns traços: ambos “descobrem-se como causa inconsciente de males que não só nunca pensaram cometer como tentaram evitar: Édipo, ao fugir de Corinto para evitar a morte do pai e a união com a mãe, vai ao encontro do seu destino; Dejanira, para evitar perder Héracles, em função de quem existe, cava a sua ruína total". 9 E ainda assim, ela não parece encaixar-se perfeitamente como heroína trágica por ter consciência de que "não é bom encolerizar-se" (v. 552), arranjando uma solução alternativa para pôr fim à dor de esposa preterida. Mais além, foge à definição de Knox, pois que sua decisão de mandar a túnica enfeitiçada ao esposo não é reprovada por ninguém. $\mathrm{O}$ coro, pelo contrário, mostra-se conivente com sua resolução.

Muito da excepcionalidade da peça deve-se também à nebulosa e carregada atmosfera e à presença obstinada de um material mítico abarrotado de figuras monstruosas. À memória dos personagens são trazidos monstros que fizeram parte de seus passados: Aqueloo, divindade fluvial de tripla forma (homem, touro e serpente) e primeiro pretendente de Dejanira, o centauro Nesso e, de forma mais abreviada, a Hidra de Lerna, Équidna, o Leão de Nemeia, Cérbero e os centauros, todos eles há muito derrotados por Héracles. À diferença das personagens femininas de Eurípides e Ésquilo mencionadas no princípio do texto, não se trata de seres humanos fisicamente normais, mas de seres míticos de corpo disforme e temíveis por sua violência e capacidade de causar danos.

Das figuras que ilustram a violência elemental, Aqueloo é o primeiro a surgir. Não completamente diferenciado das forças da natureza (é a animalização de um rio), é de uma monstruosidade extrema: um misto das raças taurina, ofídia e humana, a que ainda se acrescentam jorros de água viva a brotar das faces de barba espessa (v. 15). O centauro Nesso desponta mais tarde na peça, quando Dejanira retoma da memória o episódio da travessia do rio Eveno. Ele é referido como $\theta \hat{n} \rho$ (v. 556, 568, 662, 680, 707, 935,1162 ), termo que pode ser tomado no sentido primeiro ("besta"), como faz Charles

\footnotetext{
${ }^{8}$ É preciso assinalar, no entanto, que a referida relação de complementaridade não faz de As Traquínias "uma mera tragédia doméstica sobre um casamento infeliz". Cf. Segal, op. cit., p.28 - minha tradução.

${ }^{9}$ Cf. As traquínias: introdução à tradução de Maria do Céu Zambujo Fialho, p. 11.
} 
Segal, mas que julgamos mais adequado entender como "monstro". Sobre seus atributos físicos, o autor não se estende muito além do "peito cabeludo" (v. 557).

Só no êxodo da peça a caracterização dos monstros é mais bem precisada, quando Héracles relembra os feitos do passado (v. 1089-1102). O herói atrela propriedades específicas a cada um dos monstros em particular, mas ao que tudo indica a maior parte dos atributos são em geral compartilhados por todos eles, conformando o que aqui entendo como uma espécie de suma das "teses" de Sófocles acerca da monstruosidade. Em primeiro lugar, os monstros são delineados como criaturas

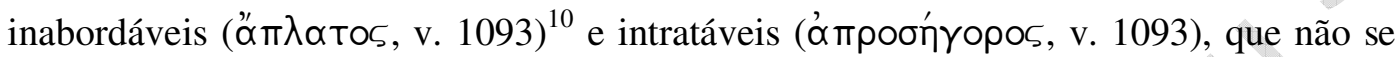

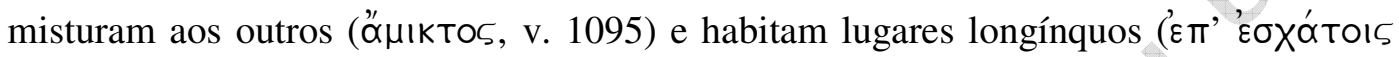

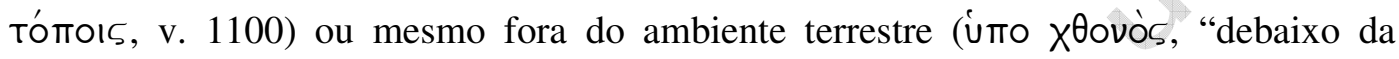
terra", v. 1097). Poder-se-ia dizer que constituem "uma incorporação do Fora, do Além - de todos aqueles loci que são retoricamente colocados como distantes e distintos, mas que se originam no Dentro". ${ }^{11}$ Héracles qualifica-os como desmedidos (üßpıotís, v. 1096) e desregrados (óvouos, v. 1096), seres híbridos - frequentemente de natureza

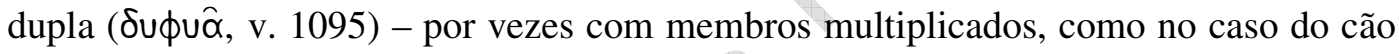

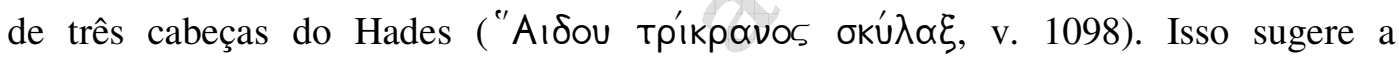
irredutibilidade a leis, à ética ou à política. Afinal, os monstros recusam-se a "fazer parte da 'ordem classificatória das coisas' (...). São híbridos que perturbam, híbridos cujos corpos externamente incoerentes resistem a tentativas para incluí-los em qualquer estruturação sistemática"12 e que com suas naturezas múltiplas fazem ruir as classificações e diferenciações, em especial as de gênero e raça. Constituem, por fim,

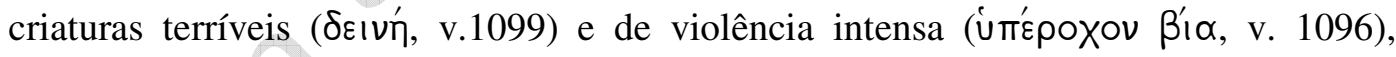
deitadas fora do mundo civilizado pelo pavor que sua brutalidade desordenada provoca.

Uns tais seres atemorizantes não são meras peças decorativas, mas itens essenciais em uma das mais atrevidas e poderosas criações da poesia dramática grega e se não forem levados totalmente a sério podem conduzir a erros de interpretação e à sub-valorização da peça. ${ }^{13}$ Que não se considerem, pois, as mencionadas criaturas de natureza híbrida exclusivamente instrumentos de assombro. Como dantes dito, um de seus papéis cardeais é evocar o limiar entre mundos opostos.

\footnotetext{
${ }^{10}$ Os termos gregos correspondentes foram mantidos no singular, apesar da sua ampla aplicabilidade por nós defendida.

${ }^{11}$ Cf. Cohen, op. cit., p. 32.

${ }^{12}$ Cf. Cohen, op. cit., p. 30.

${ }^{13}$ Cf. Segal, op. cit., p. 26.
} 
O exemplo dos centauros, metade homens, metade bestas, deixa clara a existência de uma região limítrofe entre o homem e a besta. E se os monstros ocupam a fronteira entre civilização e instintos animais primitivos não há de ser por acaso. Eles aí se alojam para dar a conhecer aos homens a própria condição humana, a qual ilustram e alegorizam. Mostram - e mostrar é, desde a raiz, o seu fim - que os homens não estão a salvo da bestialidade, por mais que isolem bestas e monstros nos confins do mundo. Portam a chocante notícia de que a racionalidade e a civilização são barreiras frágeis contra os instintos violentos e destrutivos que os humanos compartilham com os animais.

Para fazer o problema saltar aos olhos dos homens, Sófocles apresenta a monstruosidade nas Traquínias sob formas ainda mais complexas. No tempo presente em que se desenrola a história, restringe os monstros mitológicos a viverem tão somente na memória de Dejanira e Héracles. Eles principiam enterrados num passado tão longínquo quanto as mais distantes margens da geografia e do discurso, onde é costume sejam alojados monstros. Para lá foram expulsos... Mas eles sempre retornam. ${ }^{14}$ Num certo ponto da trama, é-nos revelada a existência de um filtro com que Nesso houvera presenteado Dejanira. O filtro tem em si cristalizada a combinação do sangue do centauro ao veneno da Hidra de Lerna: é ele próprio o monstro, que permanece em estágio estacionário por anos, aparentemente impotente. Mas basta que Dejanira exume de sua lembrança o filtro do centauro e presenteie o esposo com uma túnica untada pela mistura para que a monstruosidade latente tome corpo. Isso sucede de forma bastante irônica. Héracles, domador de bestas, é desta feita o domado. É abatido justamente pelos monstros que outrora derrotara. Quem “o tortura e caustica” (v. 840) é o aguilhão de Nesso, o qual, sob a aparência de túnica enfeitiçada, inflige-lhe um mal recorrentemente chamado de vóoos, "doença” (v. 853, 980, 1014, 1030, 1120). Quando Héracles surge na cena, acometido pela doença, é como se trouxesse consigo os monstros do passado, sedentos de vingança. Um ancião que acompanha o cortejo de Héracles cria a imagem de uma fera que adormece enquanto Héracles também dorme: "Não o acordes do sono em que caiu: irás provocar e reacender a terrível doença ( $\delta \varepsilon ı$ ท̀ vóoos) que o alucina, meu filho!" (v. 979-980). Uma vez despertada pelas palavras de Hilo, a fera torna a atacar o corpo de Héracles.

\footnotetext{
${ }^{14}$ Cf. Cohen, op. cit., p. 55.
} 
O coro traz um detalhe importante sobre o mal do filho de Zeus: "Foi Cípris que, operando em silêncio, se revelou como autora manifesta destes fatos" (v. 860-861). Héracles não foi apenas vítima da vingança dos monstros de seu passado. A questão é mais profunda. Assim como Nesso e Aqueloo haviam-se lançado contra a esposa de Héracles por ação de um ímpeto sexual, também o herói foi tomado, ele mesmo, pelo poder brutalizante e destrutivo de Eros e Cípris. Primeiramente, inspirada por Eros (v.

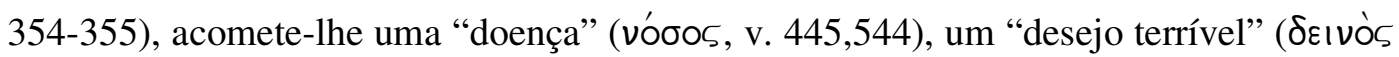
i $\mu \varepsilon \rho \circ$, v.476) que faz transbordar sua parcela bestial e leva-o a destruir Ecália e a tomar Íole como cativa. O arauto Licas, mesmo sem presciência do que está para acontecer ao filho de Zeus num futuro próximo, resume bem a situação: "É que o homem que tudo vence com a força do seu braço, pelo amor desta jovem se deixou de todo vencer" (v. 488-489). Assim é que, antes mesmo de aparecer em cena, Héracles já dá claros indícios de sua monstruosidade.

A princípio, a doença era paixão invisível, confinada ao íntimo do herói, de forma que o arauto que leva notícias de Héracles a Dejanira diz-lhe que este estava robusto, vivo e próspero, sem qualquer doença (v. 235-236). Ao menos era o que aparentava. Mais tarde, porém, Eros dá a conhecer sua outra face. Acrescenta àquela paixão uma sequela física e visível, através da intersessão do filtro, que não contém em si simplesmente uma monstruosidade latente. Numa análise mais profunda, no sangue de Nesso e no veneno da Hidra vive o próprio Eros, cujo poder monstrificante abate Héracles com uma dor agonizante e o conduz à inevitável morte. E uma vez incidindo justamente sobre Héracles - herói famoso por sua grande força física - a doença traz consigo a reflexão sobre a fraqueza do vigor heroico diante do poder sobrepujante das forças da natureza.

Nesta tragédia, é a força colossal do instinto sexual o que produz a transgressão. É ela que faz com que monstros saiam de seus recônditos para o incômodo do homem. Até encontrar Dejanira, a brutalidade de Nesso era latente. O centauro convivia pacificamente com os humanos. Costumava atravessar a corrente profunda do Eveno transportando os homens em seus braços, mediante pagamento de salário (v. 557-560). O furor imperou, contudo, quando Eros operou sobre ele. De forma semelhante, na centauromaquia do livro XII das Metarmofoses de Ovídio, os centauros convidados para as bodas do lápita Pirítoo a princípio comportavam-se civilizadamente. Mas a visão de belas mulheres aciona seus instintos sexuais que, catalisados pela ação do vinho, 
convertem-nos em selvagens e violentos saqueadores de esposas. A força incomensurável do amor vê-se outrossim simbolizada pelos mitos de metamorfose e de seres monstruosos do terceiro livro das Geórgicas de Virgílio. Ali, os aguilhões da paixão cega vitimizam homens e bestas, derrubando as barreiras entre eles. Com efeito, o livro conta com histórias como a de Io, que vinculam paixão e ciúmes com a perda de identidade humana, ${ }^{15}$ mas oferece igualmente episódios envolvendo animais, tal o das éguas enfurecidas sob a inspiração de Vênus, que devoram os membros de Glauco com as mandíbulas e engravidam sem a fecundação dos machos. ${ }^{16}$ Nas Geórgicas, até mesmo um deus pode ser simbolicamente transformado em animal por força do instinto sexual, como é o caso de Saturno. ${ }^{17}$

Os monstros desempenham importante papel ao prenunciarem que Eros rege o combate primordial entre homem e besta. Nas Traquínias, antes de Héracles ser acometido, Aqueloo, Nesso e a Hidra já o haviam sido. E através das narrativas dos eventos passados em que jazem esses seres mitológicos e das descrições poéticas de ações presentes, "a peça cria uma série de analogias entre os temas psicológicos centrados em Eros e os conflitos de humanidade e bestialidade no plano de fundo do mito dos trabalhos de Héracles". ${ }^{18}$

Conforme aponta Segal, a túnica é o elo mais óbvio entre esses dois aspectos da tragédia:

de um lado as emoções humanas expressas de forma naturalística, de outro as forças elementais apresentadas miticamente. Ela é, antes de tudo, um encantamento amoroso, o último recurso de uma mulher desesperada visando a recuperar o amor do seu marido. Mas ela também retoma a violência elemental do Centauro, fogo e sangue destrutivo, a Hidra, escuridão. Quando Dejanira expõe ao sol a lã com a qual unta a túnica, o "fervilhar" da "espuma coagulada" (702) lembra o Centauro e seu "sangue coagulado" (572). (...) O "fervilhar" sugere a turbulência íntima e emocional da paixão, mas ele também expressa as energias desregradas do mundo primitivo ao qual o Centauro pertence. Portanto, ele caracteriza os efeitos físicos do veneno do Centauro, descrito no terceiro estásimo como suas "esporas mortais, traiçoeiros e fervilhantes" (839-840). A mistura de metáforas cria um rico complexo associativo da luxúria de Héracles (a agitação emocional do "fervilhar"), o veneno do Centauro e a

\footnotetext{
${ }^{15}$ Cf. Geórgicas, III, 146-153.

${ }^{16}$ Cf. Geórgicas, III, 266-279.

${ }^{17}$ Cf. Geórgicas, III, 89-94.

${ }^{18}$ Cf. Segal, op. cit., p. 32 (minha tradução).
} 


\section{nuntius antiquus}

inversão da conquista das bestas pelo homem como o homem-cavalo aplica "esporas" e "aguilhões" (kéntra) ao conquistador humano. ${ }^{19}$

Mas o estudo do monstruoso nesta tragédia pode levar ainda a conclusões mais ousadas. Voltemo-nos para Héracles, herói conhecido por sua força física sobrehumana, com a qual extermina monstros e livra o mundo da ameaça que eles representam. Sófocles caracteriza-o quase exclusivamente em termos de sua força física. Mas a força que o mito dos doze trabalhos aponta como destinada a proteger os homens e extirpar bestas passou a servir a outros fins, voltando-se exclusivamente para o individual, como na destruição de Ecália, no assassinato de Ífito e na tomada de Íole como cativa. Com essa mudança radical, o herói passou a representar ele mesmo uma ameaça para o mundo civilizado e para os padrões da sociedade, que prescreve regras e limites a serem cumpridos até mesmo por um filho de Zeus. A brutalidade descontrolada de Héracles transformou-o num monstro como aqueles contra quem costumava combater. Um monstro que não condiz com o ambiente doméstico, com a vida em família e que contrasta demais com a esposa Dejanira, tão civilizada, comedida e cheia de compaixão. Ao contrário de Dejanira, Héracles é incapaz de refrear a cólera e o desejo de vingança, como fica patente numa conversa com o filho, em que lhe pede:

Sê para mim um verdadeiro filho: não conserves o respeito pelo nome de tua mãe. Vai ao palácio buscar aquela que te deu à luz e passa-a das tuas mãos para as minhas, para que eu saiba com nitidez o que te faz sofrer mais: ver o meu corpo desfigurado ou o dela, quando a punir com justiça. ${ }^{20}$

Ele age mesmo como se estivesse à parte do mundo humano e doméstico do qual faz parte Dejanira. O abismo entre os dois fica ainda mais óbvio com o artifício do tragediógrafo de não os por jamais juntos em cena, como sendo incompatíveis o mundo civilizado de Dejanira e a rudeza animalesca de Héracles. Para um ser como ele, não há lugar no ô̂kos, assim como é questionável a utilidade da primeva e individualista ética heroica no contexto da pólis do quinto século.

Héracles representa, certamente, a fusão do exterminador de monstros e do monstro numa só figura, a qual desencadeou o colapso das barreiras fundamentais que protegiam e mantinham a ordem do mundo civilizado afastando-o da desordem e da violência. Mas, no fim da peça, dá-se uma sutil mudança no quadro: a civilização que

${ }^{19}$ Cf. Segal, op. cit., p.32-33.

${ }^{20}$ Cf. Eurípides, op. cit., v. 1065-1069 (minha tradução). 
submetera a um tal perigo, no fim, ele a salva. Quando privado da força física (fundamento de sua monstruosidade) ele então é transformado. Manifesta uma preocupação com a união da família que sua rudeza jamais o permitira ter. A força desmesurada que lhe garantia uma vida quase sem leis, abandona-o, constrangendo-o a aceitar a lei divina; e é por isso que deixa de debater-se e aceita a morte voluntariamente, como cumprimento da vontade de Zeus. Ao fazê-lo, oferece a si mesmo como vítima do sacrifício expiatório de que o restabelecimento da ordem precisava. Sacrifício esse que funciona como purificação da violência, expiação de seus atos desmesurados e, acima de tudo, como restaurador da barreira entre homem e besta, que nunca deveria ter sido derrubada.

\section{Referências}

CIDRE, E. R. La mujer vengadora como monstruo. La deshumanización de Hécuba en la obra homónima de Eurípides. Argos. Buenos Aires, n. 26, p.123-133, 2002.

COHEN, J. J. A cultura dos monstros: sete teses. In: DONALD, J.; HUNTER, I.; COHEN, J. J.; GIL, J. Pedagogia dos Monstros. Os prazeres e os perigos da confusão de fronteiras. Tradução de Tomaz Tadeu da Silva. Belo Horizonte: Autêntica, 2000, p. 25-60.

KNOX, Bernard. The heroic temper. Studies in sophoclean tragedy. Berkeley and Los Angeles: University of California Press, 1992, p.1-61.

SEGAL, Charles. Heroic values in the "Trachinian Women". In:

Sophocles' tragic world. Divinity, nature, society. Cambridge, Mass.: Harvard University Press, 1998, p. 26-68.

SÉNECA. De la cólera. Introducción, traducción y notas de Enrique Otón Sobrino. Madrid: Alianza Editorial, 2000.

SÓFOCLES. As traquínias. Tradução de Maria do Céu Zambujo Fialho. Brasília: Editora Universidade de Brasília, 1996.

. Les Trachiniennes-Antigone. Texte établi par A. Dain et trad. par P. Mazon. Paris: Les Belles Lettres, 1955. Tome I. 